\title{
Beijos, atos, orgasmos e telas: o sexo em exibição*
}

\author{
Carolina Parreiras**
}

Se há um tema recorrente nos escritos de Linda Williams, este certamente é o sexo. Já em 1989, ano da publicação de seu mais conhecido livro - Hard Core. Power, pleasure, and the "frenzy of the visible" -, ela traça como objetivo entender as diferentes configurações do gênero pornográfico, especificamente as produções cinematográficas heterossexuais hard-core ${ }^{1}$ (comerciais ou não, como é o caso dos stag movies ${ }^{2}$ ) e desse modo contribuir para a escrita de um viés da história desse que é considerado por muitos uma parte menor ou menos importante do cinema. Sob a influência do pensamento de Foucault, ela acredita que os filmes pornográficos seriam mais um exemplo dos intricados mecanismos de poder que produziriam determinados prazeres e saberes.

\footnotetext{
* Resenha de Williams, Linda. Screening Sex. Durham/London, Duke University Press, 2008, 412p. Recebido para publicação em agosto de 2010, aceito em setembro de 2010.

** Mestre em Antropologia Social pela Unicamp e doutoranda em Ciências Sociais pela mesma universidade. carolparreiras@gmail.com

1 A consagrada divisão do gênero pornográfico em soft core e hard core tem como uma de suas bases o discurso jurídico, responsável pela criação do termo hard core. O soft core aparece por contraposição, nomeando as produções com sexo implícito, sendo correntemente associado ao erotismo. Já o hard core se refere aos materiais com sexo explícito, nos quais os atos e órgãos sexuais são mostrados com detalhamento. É bom lembrar também que estas nomenclaturas se mantêm pela ação do mercado, sendo que elas funcionam como meio de segmentá-lo e deixar visível que tipo de produto está sendo produzido.

2 Produções amadoras em vídeo, ilegais e exibidas fora dos circuitos cinematográficos convencionais.
}

cadernos pagu (35), julho-dezembro de 2010:371-378. 
Beijos, atos, orgasmos e telas

No epílogo de Hard Core escrito para a edição de 1999, Williams oferece alguns dos insights que darão base ao seu argumento em Screening Sex. O principal ponto apresentado ali é a ideia de on/scene. Nessa primeira formulação, o termo aparece como o marcador das controvérsias em torno das representações sexuais, o responsável por tensionar as noções de público e privado e, consequentemente, do que é chamado de lascivo, pruriente ou obsceno (que significa literalmente off/scene).

$\mathrm{O}$ argumento apresentado em Screening Sex caminha por um sentido semelhante e tem no conceito de on/scene a base para grande parte da discussão proposta. Mas antes de partir para a conceituação teórica é interessante pensar no modo como o livro foi construído. Em linhas gerais, o objetivo central é contar a história da exibição do sexo em filmes produzidos principalmente nos Estados Unidos no período de cerca de um século.

Já na Introdução, a autora faz a ressalva de que ela não pretende fornecer uma história completa da exibição do sexo em produções cinematográficas e que os filmes escolhidos para a análise são trabalhos que marcaram períodos ou momentos na história do cinema. Além disso, ela também ressalta que muitos deles despertaram nela - literal ou figurativamente - alguma forma de "saber carnal"3 (carnal knowledge). A discussão proposta passa então por essa localização da própria autora, sendo que, na maior parte dos capítulos, ao descrever os filmes, ela parte de reminiscências sobre os momentos em que os viu pela primeira vez, tentando mostrar os sentimentos, as sensações $e$ os pensamentos que provocaram. Assim procedendo, ela claramente se situa em relação à análise: os pontos de vista contidos no livro

3 Saber carnal tem como definição clássica intercurso sexual, coito, cópula que visa a procriação. Do modo como Williams o emprega, o termo quer especificar uma série de trocas mediadas entre os corpos que assistem e aqueles encontrados na tela. O termo evoca um conhecimento corporificado não apenas dos corpos que se tocam na tela, mas também do deleite que pode provocar naqueles que assistem. A referência para essa formulação são as produções de Vivian Sobchack sobre embodiment e cinema. 
são de uma mulher branca, heterossexual, norte-americana, com influências teóricas diversas que vão desde Foucault e Bataille, passando pela psicanálise freudiana, pela teoria crítica com Walter Benjamim, pelas formulações feministas e por estudos sobre mídias.

No percurso escolhido para entender a exibição (ou não) do sexo, Williams constrói um texto que se fosse transformado em filme forneceria um longo e denso documentário sobre as maneiras como o sexo foi colocado em discurso nas produções cinematográficas desde os seus primórdios. A organização dos capítulos proporciona, ao longo da leitura, a sensação de estar visualizando as cenas descritas pela autora, bem como o contexto mais amplo em que elas foram concebidas. Facilita esse processo, principalmente para os não muito inteirados sobre a história do cinema ou sobre os filmes citados, o uso cuidadoso de imagens de diversas das produções analisadas e sua preocupação em dissecar as cenas, apresentando-as em detalhes juntamente com análise dos comentários de produtores, diretores e críticos de cinema.

A divisão dos capítulos se baseia na delimitação de eras na produção cinematográfica. O critério para o estabelecimento de cada era não é exatamente cronológico, visto que em termos de datas ocorrem interpenetrações entre elas e um único período pode apresentar manifestações diferentes em relação à exibição do sexo.

O primeiro capítulo se concentra na era do beijo ou como Williams coloca já no título, o período da "longa adolescência americana". Beijos foram durante muito tempo a única manifestação com conotação sexual mostrada em filmes. Assim a autora passa por produções que vão desde o primeiro beijo do cinema - The Kiss (Thomas Edison, 1896), passando pelo cinema mudo com Flesh and The Devil ${ }^{4}$ (Clarence Brown, 1927), por produções clássicas de Hollywood como Casablanca (Michael

4 O Demônio e a Carne. 
Beijos, atos, orgasmos e telas

Curtiz, 1942) e Notorious ${ }^{5}$ (Alfred Hitchcock, 1946) até o não tão mainstream Kiss (Andy Warhol, 1963).

No segundo capítulo, a intenção é mostrar como os atos sexuais e o que ela chama de "saber carnal" chegaram às telas norte-americanas entre os anos de 1961 e 1971. É salientada a importância dos filmes estrangeiros que serviram de inspiração para os diretores norte-americanos começarem a colocar sexo simulado em suas produções. Para que isso acontecesse, atuaram em conjunto a força da revolução sexual que acontecia no período, bem como uma série de mudanças na produção $e$ comercialização dos filmes. Para colocar na tela essas novas performances, alguns recursos técnicos foram importantes, como por exemplo, a utilização de interlúdios sexuais. ${ }^{6}$ Dois filmes são o foco central da análise: The Graduate ${ }^{7}$ (Mike Nichols, 1967) e Midnight Cowboy (John Schlesinger, 1969). A parte final desse capítulo é dedicada a produções mais independentes sexploitation $^{8}$, blaxploitation ${ }^{9}$ e avant-garde ${ }^{10}$.

O terceiro capítulo é dedicado à análise de três filmes: Last Tango in Paris ${ }^{11}$ (Bernardo Bertolucci, 1972), Deep Throat ${ }^{12}$ (Gerard Damiano, 1972) e Boys in the Sand (Wakefield Poole, 1971). Grande parte da discussão gira em torno do momento inicial da

5 Interlúdio.

6 Interlúdio sexual significa que o registro sexual era feito em um tempo distinto do restante do filme. Era comum a utilização de trilhas sonoras para os momentos de simulação de sexo.

7 A Primeira Noite de um Homem.

8 Filmes soft-core produzidos nas décadas de 60 e 70 que se caracterizavam pela exploração de temas adultos e grande exibição do corpo feminino.

9 Filmes, produzidos principalmente entre os anos de 71 e 74 , onde havia a exploração aberta do sexo racializado, com a exaltação da virilidade do homem negro e de grande quantidade de situações de violência.

${ }^{10}$ Filmes de menor exibição que mostravam atos sexuais explícitos, mas com estética e objetivos políticos e sociais bem diversos da pornografia hard-core.

${ }^{11} \mathrm{O}$ Último Tango em Paris.

12 Garganta Profunda. 
pornografia mais comercial - chamada pela autora de pornô chique - heterossexual e gay e pela apresentação das provocativas e ousadas cenas de sexo presentes em $O$ Último Tango em Paris. Já no quarto capítulo, a questão do orgasmo feminino é abordada, com o foco em filmes estrelados por Jane Fonda. A autora ainda mostra como naquele momento as idéias da sexologia em relação ao orgasmo eram importantes, especialmente nas formulações de Kinsey e Masters e Johnson, e também todo o ativismo político feminista e anti-guerra ("Make Love, not War"), com a apropriação do livro de Marcuse - Eros e Civilização.

No quinto capítulo, a atenção se volta para o filme $O$ império dos sentidos (Oshima Nagisa, 1976) que representaria a fusão dos elementos gráficos da pornografia hard-core com a narrativa erótica do amor. Esse filme é o primeiro exemplo de produção cinematográfica que fez sucesso tanto como arte quanto como pornografia, exatamente porque tensiona estes dois pólos. O sexto capítulo é talvez o que mais traga a influência da psicanálise, especialmente das formulações de Freud sobre fantasias primitivas. Williams escolhe então recortes dos filmes, que chama de "cenas primitivas" para mostrar tabus relativos ao sexo presentes nas produções de Hollywood: em Blue Velvet ${ }^{13}$ (David Lynch, 1986) é pensada a questão do sadomasoquismo $e$ em Brokeback Mountain (Ang Lee, 2005), a penetração anal.

Por fim, no capítulo 7, ela analisa filmes de arte erótica produzidos durante a década de 90 e reivindica para eles o rótulo de "arte erótica hard-core". Este tipo de produção seria extremamente gráfica, como a pornografia hard-core é, mas não utilizaria os mesmos recursos da narrativa pornográfica, como a filmagem em close-up com grande detalhamento da anatomia corporal. No capítulo final, Williams se propõe a pensar nos desdobramentos mais contemporâneos da exibição do sexo. Para tal, toma como foco a multiplicidade de telas hoje encontradas:

${ }^{13}$ Veludo Azul. 
Beijos, atos, orgasmos e telas

não há apenas a grande tela das salas de cinema, mas as telas de televisões (DVDs) e computadores (cyberporn), cada vez mais tecnológicas e interativas.

Feita essa apresentação, algumas questões que perpassam toda a obra merecem atenção. A primeira delas diz respeito ao uso do verbo to screen que tem um duplo significado: é uma projeção, uma exibição, aquilo que revela, mas também pode ser tomado como aquilo que elide e esconde. Há então na história das imagens de sexo em filmes uma relação dialética entre revelação e encobrimento. Beijos podem ser mostrados, mas há uma maneira correta de fazê-lo. Atos sexuais podem ser simulados, mas os sons do sexo devem ser elididos e por isto a necessidade de uma música. E é essa dialética que Williams tenta mostrar ao longo do livro, associando-a com um contexto político, econômico e cultural mais amplo.

Nesse contexto, aparecem momentos importantes como, por exemplo, a existência de um Código de Produção para os filmes de Hollywood (Hollywood Production Code). Este Código, atuante de 1934 a 1966, era um reflexo dos variados tabus da sociedade em relação ao sexo e proibia que os filmes mostrassem ou mesmo inferissem "formas baixas de relação sexual" identificadas como "beijos excessivos e lascivos", "sedução ou estupro", "perversão sexual", "cenas de nascimento", "doenças venéreas", "nudez completa" e "exposição indecente". Outro ponto que Williams destaca é que o Código não permitia a miscigenação, vetando toda e qualquer representação de atos sexuais inter-raciais.

Em substituição ao Código, foi criada em 1968 a Motion Picture Association of America (MPAA). Sua principal decisão foi criar um sistema de classificação dos filmes, tentando adequá-los às diferentes audiências. A primeira divisão era entre filmes para adultos e filmes para crianças. A MPAA é uma das responsáveis também pelo desenvolvimento da categoria "X", a qual passou a ser utilizada, após o boom das produções pornográficas, para caracterizar esse tipo de produção. 
Também faz parte do contexto mais amplo, a revolução sexual a partir dos anos 60. Era clara a relação das ideias de libertação sexual com a contracultura anti-guerra, anti-racismo, anticapitalista $e$ anti-patriarcal. É nesse momento que o movimento feminista, os debates (morais, jurídicos e feministas) em torno dos conceitos de pornografia $e$ obscenidade $e$ as formulações de sexólogos se tornam importantes e permitem uma mudança nas convenções morais operantes, além de permitirem a produção de filmes como $O$ último tango em Paris, Garganta Profunda, Barbarella e $O$ império dos sentidos.

Em relação aos desenvolvimentos mais recentes da exibição de sexo, Williams traz importantes considerações sobre os avanços tecnológicos e o modo como eles proporcionam mudanças na maneira como o sexo é visto e sentido. O desenvolvimento do cyberporn e o crescimento do consumo de filmes em ambiente privado seriam duas das mais visíveis modificações ocorridas a partir dos anos 90. E elas têm um impacto considerável ao modificar a relação público/privado e as maneiras de recepção dos filmes. Não se trata mais apenas de uma audiência defronte a uma grande tela partilhando pública e grupalmente da exibição, mas sim de pessoas que podem estar em seus quartos, sozinhas ou acompanhadas, com a tela de seu computador, conectadas à internet $e$ interagindo das mais diferentes formas com o que vê $e$ sente. Ela reconhece ainda o papel da internet na crise da indústria pornográfica mais tradicional. A experiência de interatividade (e exemplos são os sites de sexo via webcam) mais ampla talvez seja o ponto que confere ao on-line uma diferenciação em relação às técnicas anteriores de interação expectador - tela de cinema.

Apesar de não acreditar que seja possível falar em uma hegemonia de uma das telas, ela afirma que o entendimento da exibição do sexo hoje deve considerar múltiplas possibilidades que incluem clicar, digitar, escolher e até mesmo ver o público assumindo o papel diretor: filmando, escolhendo os atos, as cenas $e$ as interações. 
Beijos, atos, orgasmos e telas

Ao montar o percurso apresentado no livro, Williams possibilita relacionar sexo em sua forma cinematográfica não apenas à pornografia - sua manifestação mais conhecida, debatida e polêmica - ou ao erotismo, mas pensá-lo desde os quase inocentes beijos do cinema mais clássico, passando pelos orgasmos femininos cuja figura símbolo é Jane Fonda, até as relações em tempo real via internet com cybersex e cyberporn.

Assim, faz sentido retornar à ideia de on/scene: a tese proposta por Linda Williams é a de que para pensar as representações sexuais na cultura norte-americana desde a invenção do cinema é necessário levar em consideração o grau em que os atos chamados um dia de obs-cenos (off/scene) foram se tornando on/scene. $\mathrm{O}$ que a autora intenciona ao propor $\mathrm{o}$ termo on/scene é evitar julgamentos apressados e usos levianos do termo obsceno. Seu percurso argumentativo, narrativo e analítico vem reiterar essa proposta: são muitos os modos de se retratar atos sexuais e essa profusão de imagens não pode ser entendida como descolada da história cultural e social do sexo, nem fora da retórica repetidas vezes mencionada por ela de revelação $e$ encobrimento.

\section{Referências bibliográficas:}

Williams, Linda. Hard Core. Power, pleasure, and the "frenzy of the visible". Berkeley/Los Angeles/London, University of California Press, 1999. 